УДК 669.162.1

А. С. Мных, И. Г. Яковлева, М. Ю. Пазюк

Запорожская государственная инженерная академия, пр. Соборный, 226, Запорожье, 69006, Украина

\title{
ВЛИЯНИЕ УСЛОВИЙ ФОРМИРОВАНИЯ СЫПУЧЕГО СЛОЯ ЖЕЛЕЗОРУДНЫХ И БОКСИТОВЫХ МАТЕРИАЛОВ НА КОЭФФИЦИЕНТ ТЕПЛООТДАЧИ
}

\begin{abstract}
Приводятся результаты исследований направленных на изучение гранулометрического состава слоя сыпучего железорудного и бокситового материала, формирование которого осуществляется при использовании систем загрузки в виде вибрачионного и барабанного питателей в совокупности с загрузочным лотком. Определены закономерности изменения среднего диаметра частии материала по высоте слоя, подготовленного к тепловой обработке. Установлено, что тип загрузочного устройства в значительной степени влияет на характер распределения классов крупности сыпучего материала. Последнее определяет закономерность изменения величины объемного коэффициента теплоотдачи по высоте спекательной тележки.
\end{abstract}

Ключевые слова: Агломерация; Спекательная тележка; Бокситы; Средний диаметр; Коэффициент теплоотдачи; Температурное поле.

А. С. Мних, І. Г. Яковлева, М. Ю. Пазюк

Запорізька державна інженерна академія, пр. Соборний, 226, Запоріжжя, 69006, Україна

\section{ВПЛИВ УМОВ ФОРМУВАННЯ СИПУЧОГО ШАРУ ЗАЛІЗОРУДНИХ ТА БОКСИТОВИХ МА- ТЕРІАЛІВ НА КОЕФІЦІЄНТ ТЕПЛОВІДДАЧІ}

Наведено результати досліджень, які спрямовані на вивчення гранулометричного складу шару сипучого залізорудного та бокситового матеріалу, формування якого відбувається при використанні систем завантаження у вигляді вібраційного та барабанного живильників у сукупності із завантажувальним лотком. Встановлено значення зміни середнього діаметру часток матеріалу по висоті шару підготовленого до теплової обробки. Встановлено, щуо тип завантажувального пристрою в значній мірі впливає на характер розподілу класів крупності сипучого матеріалу. Останнє встановлює закономірність зміни величини об'ємного коефіцієнта тепловіддачі по висоті палети.

Ключові слова: Агломерація; Палета; Боксити; Середній діаметр; Коефіцієнт тепловіддачі; Температурне поле.

This work is licensed under the Creative Commons Attribution International License (CC BY). http://creativecommons.org/licenses/by/4.0/

\section{ПРОБЛЕМА И ЕЕ СВЯЗЬ С НАУЧНЫМИ И ПРАКТИЧЕСКИМИ ЗАДАЧАМИ.}

На сегодняшний день наблюдается снижение спроса на сталь на мировых рынках, последнее привело к демпингу цен странами Азиатского региона. Следует отметить, что удельные расходы топлива в агломерационных машинах, эксплуатирующихся в странах бывшего СНГ, существенно выше, чем этот же показатель в развитых странах.

С целью обеспечения конкурентоспособности выпускаемой отечественными металлургическими предприятиями продукции, на фоне общего подорожания энергетических ресурсов, необходимо детальное изучение и совершенствование теплового режима процесса производства агломерата. Последнее позволит изучить закономерности и факторы, влияющие на распределение химических компонентов и топлива по высоте пирога, проанализировать температурный режим агломерации отдельных горизонтов спекаемой шихты и разработать рекомендации, направленные на повышение энергоэффективности аглопроцесса.

\section{АНАЛИЗ ИССЛЕДОВАНИЙ И ПУБЛИКАЦИЙ.}

В последнее время широкое распространение при изучении физических объектов и тепловых процессов, протекающих в них, получило конечноэлементное моделирование [1,2]. Современный уровень развития компьютерной техники, а также численно-аналитических методов решения инженерных задач позволяет реализовать наиболее точную картину ввода и последующего перераспределения теплоты при агломерации в трехмерной модели, разработанной на основе экспериментальных и расчетных данных. Для расчета используется метод конечных эле- 
ментов (МКЭ) [3], реализованный в программнометодическом комплексе ANSYS.

\section{ПОСТАНОВКА ЗАДАЧИ.}

Температурные поля в процессах тепловой обработки плотного слоя сыпучего материала во многом зависят от величины коэффициента теплоотдачи, определяющего интенсивность развития тепловых явлений. Агломерация железорудных и бокситовых материалов, производится на машинах конвейерного типа, загрузка сыпучего материала осуществляется различными загрузочными системами, что предопределяет распределение классов крупности материала по высоте и ширине спекательных тележек. Известно [4], что величина коэффициента теплоотдачи в значительной степени зависит от крупности материала, подвергаемого тепловой обработке.

Таким образом, определение значений коэффициента теплоотдачи по высоте агломерируемого слоя является важной научно-практической задачей, что позволит подойти к моделированию тепловых процессов, протекающих в спекаемом слое $[5,6]$.

Для достижения поставленной цели необходимо решить следующие задачи:

1. Исследовать фракционный состав слоев железорудной и бокситовой шихты, подготовленной к тепловой обработке;

2. Определить изменение среднего диаметра частиц сыпучего материала по высоте слоя;

3. Рассчитать значения коэффициента теплоотдачи, по горизонтам агломерируемого железорудного и бокситового сыпучего материала.

\section{ИЗЛОЖЕНИЕ МАТЕРИАЛОВ И РЕЗУЛЬТАТЫ.}

Гранулометрический состав промышленного сырья характеризуется распределением частиц материала, его сегрегацией по классам крупности, то есть по размеру, который оценивается по величине так называемого эквивалентного диаметра. Определение гра- нулометрического состава материала осуществляют при помощи ситового анализа, который заключается в просеивании пробы материала через ряд сит с выделением надрешеточного продукта на каждом сите. Для увеличения достоверности ситового анализа, выполняют несколько рассевов проб материала, отобранных из разных точек исследуемой массы.

При автоматическом анализе фракционного состава сыпучих материалов в производственных условиях обычно контролируют средний диаметр частиц материала, его связь с содержанием отдельных фракций сыпучей массы характеризуется следующим уравнением:

$$
\mathrm{d}_{\mathrm{cp}}=\sum_{i=1}^{n} \mathrm{~d}_{\mathrm{i}} \Phi_{\mathrm{i}}
$$

где: $\mathrm{d}_{\mathrm{cp}}$ - средний диаметр частиц i-й фракции материала, мм; $\Phi_{\mathrm{i}}$ - содержание i-й фракции в массе сыпучего материала, \%; $n$ - количество фракций.

Одно и то же значение $\mathrm{d}_{\mathrm{cp}}$ может быть получено при различных функциях распределения частиц полидисперсного материала, что определяется свойствами сыпучих материалов, а также условиями их дробления, усреднения и классификации. Поэтому представляет интерес теоретическое исследование механизма разделения классов крупности полидисперсного железорудного и бокситового материала в процессе его ситового анализа.

С целью исследования указанного механизма разделения зернистой массы проведены эксперименты на агломашинах № 1, 2, 4, 5, использующих для загрузки систему, состоящую из вибрационного либо барабанного питателя в совокупности с отражательным листом. Экспериментально полученное, с использованием ситового анализа для условий аглофабрики комбината «Запорожсталь», содержание фракций в агломерационной шихте для условий АM № 2 представлено в таблице 1 .

Таблица 1 - Фракционный состав шихты на агломашине №2

\begin{tabular}{|c|c|c|c|c|c|c|c|}
\hline $\begin{array}{c}\text { Место } \\
\text { отбора }\end{array}$ & $\begin{array}{c}\text { Горизонт } \\
\text { слоя, м }\end{array}$ & \multicolumn{7}{|c|}{ Фракционный состав шихты, \% } & $\begin{array}{c}\text { Средний } \\
\text { диаметр, мм }\end{array}$ \\
\hline & & +10 & $+8-10$ & $+5-8$ & $+3-5$ & -3 & \\
\hline & 0,1 & 3,77 & 1,89 & 8,14 & 17,57 & 68,63 & 3,74 \\
Правая & 0,2 & 4,26 & 6,04 & 15,81 & 20,43 & 52,96 & 4,16 \\
сторона & 0,3 & 5,08 & 3,88 & 15,84 & 21,61 & 53,59 & 4,59 \\
& 0,4 & 19,56 & 7,25 & 17,28 & 16,46 & 39,45 & 5,37 \\
& 0,5 & 11,67 & 6,89 & 20,19 & 26,59 & 34,59 & 8,11 \\
\hline & 0,1 & 3,52 & 1,32 & 10,28 & 30,54 & 54,33 & 3,61 \\
Середи- & 0,2 & 5,96 & 4,09 & 16,99 & 33,99 & 39,00 & 4,34 \\
на слоя & 0,3 & 8,18 & 4,73 & 19,34 & 29,46 & 38,29 & 4,72 \\
& 0,4 & 12,02 & 9,92 & 23,52 & 23,12 & 31,42 & 5,35 \\
& 0,5 & 17,32 & 7,38 & 16,35 & 19,68 & 39,28 & 7,53 \\
\hline \multirow{2}{*}{ Левая } & 0,1 & 2,69 & 1,79 & 10,27 & 23,61 & 61,63 & 4,63 \\
сторона & 0,2 & 7,05 & 3,48 & 16,99 & 24,38 & 48,09 & 4,49 \\
& 0,3 & 6,19 & 4,67 & 19,09 & 24,63 & 45,41 & 5,09 \\
& 0,4 & 13,04 & 7,84 & 20,64 & 22,04 & 36,44 & 6,24 \\
\hline
\end{tabular}


Таблица 2 - Изменения среднего диаметра частиц железорудного сыпучего материала по высоте слоя при использовании различных питателей.

\begin{tabular}{|c|r|r|r|r|r|r|r|r|r|r|r|}
\hline Высота, $\mathbf{M}$ & $\mathbf{0}$ & $\mathbf{0 , 0 5}$ & $\mathbf{0 , 1}$ & $\mathbf{0 , 1 5}$ & $\mathbf{0 , 2}$ & $\mathbf{0 , 2 5}$ & $\mathbf{0 , 3}$ & $\mathbf{0 , 3 5}$ & $\mathbf{0 , 4}$ & $\mathbf{0 , 4 5}$ & $\mathbf{0 , 5}$ \\
\hline$\left(\right.$ ВП) $\mathrm{d}_{\mathrm{cp}}$, мм & 1,5 & 2 & 2,71 & 3,31 & 3,75 & 4,08 & 4,93 & 5,6 & 6,35 & 7,04 & 8 \\
\hline$\left(\right.$ БП) $\mathrm{d}_{\mathrm{cp}}$, мм & 3,7 & 3,8 & 3,9 & 4,01 & 4,175 & 4,39 & 4,75 & 5,13 & 5,5 & 5,95 & 6,4 \\
\hline
\end{tabular}

Усредненные значения изменения среднего диаметра сыпучего материала по высоте слоя, при использовании для загрузки вибрационного (ВП) и барабанного питателя (БП) представлены в таблице 2.

В спекательном отделении аглофабрики ПАО «Запорожский абразивный комбинат» загрузка шихты ведется барабанным питателем без использования отражательного листа либо загрузочных лотков. Для анализа процесса формирования слоя шихты на аглоленте проведены экспериментальные исследования по определению фракционного состава горизонтов материала, подготовленного к спеканию.

В результате проведено три серии опытов по отбору проб шихты. Забор проб производился механическим пробоотборником высотой 300 мм, который устанавливался под поток загружаемого материала. После заполнения пробоотборник извлекался, слой делился на участки высотой 50 мм, которые аккуратно срезались и рассеивались на ситах. Результаты эксперимента № 3 приведены в таблице 3

Таблица 3 - Фракционный состав шихты для условий ЗАК.

\begin{tabular}{|c|c|c|c|c|c|c|}
\hline \multicolumn{7}{|c|}{ Опыт - 3} \\
\hline h, Mм & $\Phi(-3)$ & $\Phi(3-5)$ & $\Phi(5-8)$ & $\Phi(8-12)$ & $\Phi(+12)$ & $\sum, \%$ \\
\hline $0-50$ & 31,2 & 23,8 & 20,3 & 12,8 & 11,9 & 100 \\
\hline $50-100$ & 27,2 & 22,1 & 23,8 & 15,9 & 11 & 100 \\
\hline $100-150$ & 25,5 & 17,4 & 26,1 & 18,7 & 12,3 & 100 \\
\hline $150-200$ & 18,8 & 15,1 & 26 & 21,4 & 18,7 & 100 \\
\hline $200-250$ & 11,3 & 12,4 & 28,2 & 27,2 & 20,9 & 100 \\
\hline $250-300$ & 10,7 & 12 & 20,6 & 32,4 & 24,3 & 100 \\
\hline
\end{tabular}

Результаты определения среднего диаметра сыпучего материала по итогам проведения трех опытов представлены в табл. 4.

Таблица 4 - Изменение среднего диаметра гранул бокситовой шихты.

\begin{tabular}{|c|r|r|r|}
\hline № опыта & \multicolumn{1}{c|}{$\mathbf{1}$} & \multicolumn{1}{c|}{$\mathbf{2}$} & \multicolumn{1}{c|}{$\mathbf{3}$} \\
\hline $\mathbf{h}, \mathbf{M м}$ & $\mathbf{d}_{\mathbf{c p}}, \mathbf{M M}$ & \multicolumn{1}{c|}{$\mathbf{d}_{\mathbf{c p}}, \mathbf{M M}$} & $\mathbf{d}_{\mathbf{c p}}, \mathbf{M M}$ \\
\hline $0-50$ & 6,043 & 5,643 & 5,507 \\
\hline $50-100$ & 6,278 & 6,2065 & 5,804 \\
\hline $100-150$ & 6,21 & 6,2835 & 6,1825 \\
\hline $150-200$ & 6,7285 & 6,476 & 7,0535 \\
\hline $200-250$ & 7,3085 & 7,424 & 7,831 \\
\hline $250-300$ & 7,5145 & 8,0268657 & 8,257 \\
\hline
\end{tabular}

Для анализа тепловых процессов, протекающих в слое сыпучего материала используется объемный коэффициент теплоотдачи, его связь с поверхностным коэффициентом теплоотдачи относительно проста и представляет собой зависимость[4]:

$$
\alpha_{V}=\alpha_{F} F
$$

где $F=6(1-f) / d_{м}, \mathrm{M}^{2} / \mathrm{M}^{3}-$ для частиц шарообразной формы.
Для расчета объемного коэффициента теплоотдачи использована формула Китаева Б.И., полученная в результате обработки экспериментальных данных Фурмана С.С. по нагреву и охлаждению слоя сыпучего материала, состоящего из кусков (4-70 мм), в широком диапазоне температур (до $1100^{\circ} \mathrm{C}$ ) при изменении скорости движения продуктов сгорания в диапазоне 0,6-1,8 м/с, имеющая вид:

$$
\alpha_{V}=\frac{4,19}{3,6} \cdot 150 \cdot \frac{w_{2}^{0,9} \cdot T_{2}^{0,3}}{d_{M}^{0,75}} \cdot M^{\prime}
$$

где $w_{2}$ - скорость движения продуктов сгорания, м/с; $T_{2}$ - температура продуктов сгорания, ${ }^{\circ} \mathrm{C} ; d_{M}-$ средний диаметр частиц материала, м; $M^{\prime}-$ коэффициент, характеризующий равномерность распределения газов по поперечному сечению слоя и содержание мелких фракций, $M^{\prime}=0,3 \div 0,5$.

Результаты расчетов объемного коэффициента теплоотдачи для слоев железорудной и бокситовой шихты подготовленной к тепловой обработке, представлены на рис. 1,2.

Представленные результаты свидетельствуют о значительном влиянии степени разделения классов крупности сыпучего материала, обусловленной типом загрузочной системы. Наблюдается существенная неравномерность величины коэффициента теплоотдачи для верхних и нижних горизонтов слоя при использовании для загрузки вибрационного питателя. 
Диапазон изменения $\alpha_{V}$ в этом случае находится в пределах $2800 \div 9500 \mathrm{BT} /\left(\mathrm{M}^{3 .}{ }^{\circ} \mathrm{C}\right)$. При использовании барабанного питателя наблюдается монотонное снижение величины коэффициента, для случая агломерации железорудного материала диапазон изменения $\alpha_{V}$ составил $3300 \div 4800 \quad \mathrm{BT} /\left(\mathrm{M}^{3 .}{ }^{\circ} \mathrm{C}\right), \quad$ а бокситов

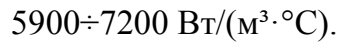

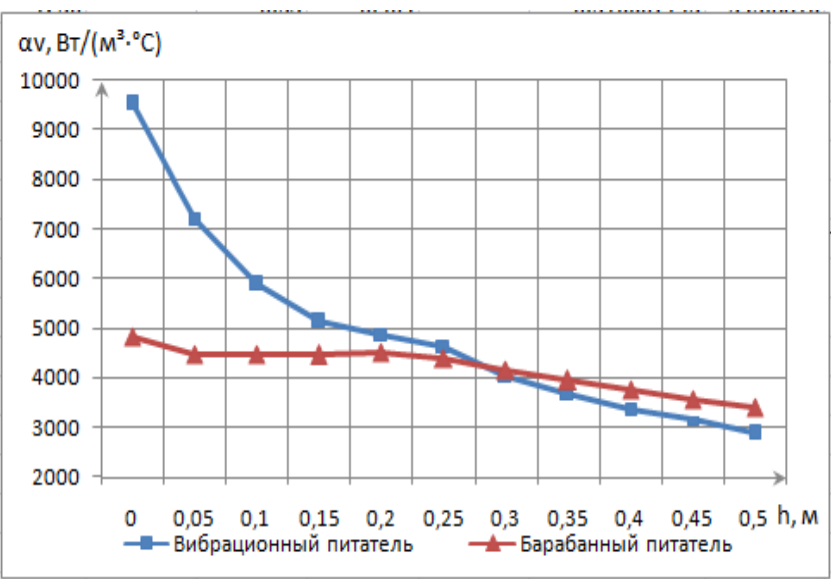

Рисунок 1 - Изменение значения $\alpha_{V}$ по высоте слоя железорудной шихты.

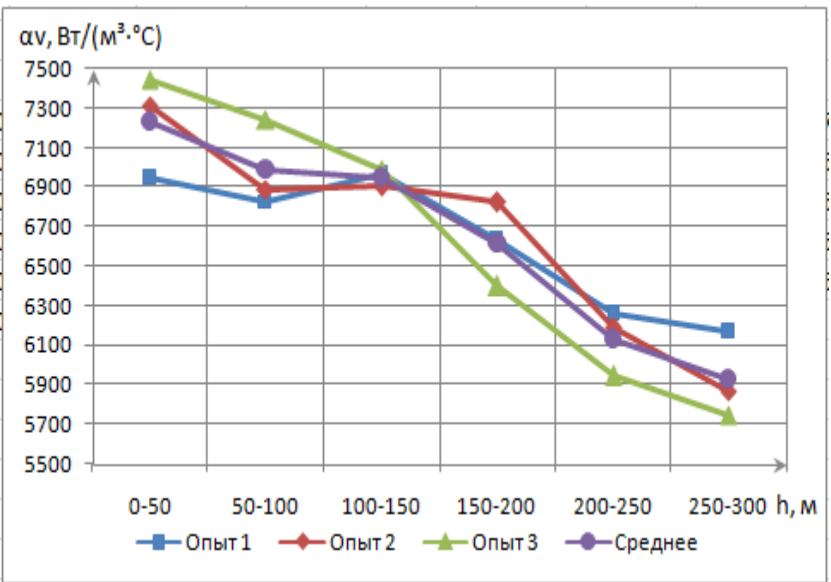

Рисунок 2 - Изменение значения $\alpha_{V}$ по высоте слоя бокситовой шихты.

\section{ВЫВОДЫ И НАПРАВЛЕНИЯ ДАЛЬНЕЙШИХ ИССЛЕДОВАНИЙ.}

В работе исследован фракционный состав слоев железорудного и бокситового материала, подготовленного к тепловой обработке. Установлены закономерности изменения среднего диаметра сыпучего ма териала по высоте слоя. Получены зависимости и диапазон изменения значений объемного коэффициента теплоотдачи по высоте слоев железорудного и бокситового сыпучего материала. Установлено существенное влияние типа загрузочной системы, обусловливающей интенсивность разделения классов крупности частиц, на величину $\alpha_{V}$ по высоте слоя.

Полученные результаты позволяют провести исследования теплового режима спекания агломерата на базе разработанной модели $[5,6]$, что позволит сформулировать рекомендации к условиям формирования слоя агломерационной шихты с целью обеспечения требуемого распределения химических компонентов и твердого топлива в каждом горизонте и стабилизации температурно-временного режима спекания агломерата.

\section{ЛИТЕРАТУРА}

1. Свет Е. В. Нестационарная задача теплопроводности в трехмерной постановке для многослойных пластин сложной формы // Вісник НТУ «ХПІ». - 2013. № 63 (1036). - c. 122-131.

2. Масловская А. Г., Сивунов А. В. Применение метода конечных элементов для моделирования эволюционных процессов теплопроводности в облученных электронными пучками полярных диэлектриках // «Компьютерные исследования и моделирование». 2012. № 4. - С. 767-780.

3. Мных А. С. Решение методом конечных элементов задачи о распределении температур в единичном объеме агломерационного слоя при заданных граничных условиях // Збірник наукових праць ДДТУ (технічні науки). - 2014. №2(25). - С.153-159.

4. Зобенин Б. Ф. Теплотехнические расчеты металлургических печей. [Текст] / Б. Ф. Зобенин, М. Д. Казяев, Б.И. Китаев и др. Учебное пособие для вузов. Изд. 2-е. М.: Металлургия, 1982, 360 с.

5. Мных А. С. Определение оптимального распределения твердого топлива в слое загружаемой шихты для выравнивания теплового режима агломерационного процесса [Текст]/ А. С. Мных // Технічна теплофізика та промислова теплоенергетика (збірник наукових праць). - 2014. вып. 6. - С. 69-79.

6. Мных А. С. Исследование тепловых процессов в агломерируемом слое бокситов в зависимости от сегрегации топлива и химкомпонентов по высоте [Текст] / А. С. Мных // Энергетика. Энергосбережение. Энергоаудит. - 2015. №6 (136). - С. 23-27.

\footnotetext{
Отримана в редакції 03.06.2016, прийнята до друку 01.07.2016
} 
A. S. Mnyh ${ }^{\bowtie}$ I. G. Yakovleva, M. U. Pazuk

Zaporizhzhya State Engineering Academy, 226 av. Soborniy, Zaporozhye, 69006, Ukraine

$\triangle$ e-mail: mnikh.a@yandex.ua, ORCID: orcid.org/0000-0001-5421-9778

\section{THE INFLUENCE CONDITIONS OF FORMATION A LAYER OF GRANULAR IRON ORE AND OF BAUXITES MATERIALS ON THE HEAT TRANSFER COEFFICIENT}

To ensure competitiveness of the domestic metallurgical production enterprises against the background of General rise in price of energy resources the detailed study and sinter production process thermal mode improvement is required. The latter will allow to perform temperature regime of the agglomeration of individual horizons of sintered charge and to develop recommendations aimed at improving the efficiency of the agglomeration process. The temperature field in the heat treatment processes of a dense layer of granular material depends largely on the magnitude of the heat transfer coefficient that defines the intensity of thermal phenomena development. Agglomeration of iron ore and bauxite materials produced on machines of conveyor type, loading of bulk material is different boot system, which determines the layer structure of the bulk material prepared for heat treatment. The results of research aimed at the study of the granulometric composition of the layer of bulk iron ore and bauxite material, the formation of which is carried out with use of loading in the form of drum and vibratory feeders in conjunction with boot tray are presented in the paper. The values of the change of the average diameter of the particles of material on the layer height are prepared for sintering. It is established that the loading device has a significant impact on the nature of the distribution of size fractions of the bulk material. The latter determines the pattern of changes in the magnitude of volumetric coefficient of heat transfer height of the pallet. The obtained results allow to carry out studies of the thermal regime of sintering on the basis of the developed model, which will formulate recommendations to the conditions of sinter charge layer formation in order to ensure desired distribution of chemical compounds and solid fuels in each horizon and stabilization of sintering temperature-time regime.

Key words: Agglomeration; Pallet; Bauxite; Average Diameter; Heat Transfer Coefficient; Temperature Field.

\section{REFERENCES}

1. Svet, E. V. (2013). Nestacionarnaia zadacha teploprovodnosti $\mathrm{V}$ trehmernoi postanovke dlia mnogosloinykh plastin slozhnoi formy [Nonstationary problem of heat conduction in three-dimensional formulation for multilayered plates of complex shape]. Visnyk NTU “KhPI”, No. 63(1036), 122-131 (in Russian).

2. Maslovskaya, A. G., Sivunov, A. V. (2012). Primenenie metoda konechnykh elementov dlia modelirovaniia evoliutsionnykh protsessov teploprovodnosti $\mathrm{v}$ obluchennykh elektronnymi puchkami polarnykh dielektrikah [Application of the finite element method for modeling the evolutionary processes of thermal conductivity in irradiated electron beams of polar dielectrics]. Komputernyie issledovania $i$ modelirovanie, No. 4, 767-780 (in Russian).

3. Mnyh, A. S. (2014). Reshenie metodom konechnih elementov zadachi o raspredelenii temperatury $\mathrm{v}$ edinichnom obiome aglomeratsionnogo sloia pri zadannykh nachalnykh usloviiakh [The decision by the finite element method to the problem of temperature distribution in the single volume of sinter layer under the given boundary conditions]. Zbirnyk naukovykh prats DDTU, No. 2(25), 153-159 (in Russian).

4. Zobenin, B. F. (1982). Teplotekhnicheskie raschety metalurgicheskikh pechei [Thermal calculations of metallurgical furnaces]. Moscow: Metalurgiya, 360 (in Russian).

5. Mnyh, A. S. (2014). Opredelenie optimal'nogo raspredeleniia tverdogo topliva $\mathrm{v}$ sloe zagruzhaemoi shikhty dlia vyravnivaniia teplovogo rezhima aglomeratsionnogo protsessa [Determination of the optimal distribution of the solid fuel layer downloadable charge to align the thermal regime of the sintering process]. Tekhnicheskaia teplophizika i promyshlennaia teploenergetika, No. 6, 69-79 (in Russian).

Mnyh, A. S. (2015). Issledovanie teplovyh protsessov v aglomeriruemom sloe boksitov $\mathrm{v}$ zavisimosti ot segregatsii topliva i khimkomponentov po vysote [The study of thermal processes in aglomeration layer of bauxite, depending on the segregation of fuel and chemical components height]. Energetika, Energosberezhenie, Energoaudit, No. 6(136), 23-27 (in Russian). 